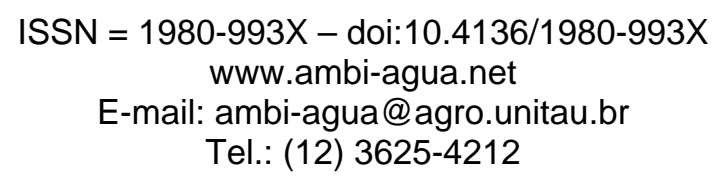

\title{
Análises de Componente Principal e de Agrupamento para estudo de ventos para a geração de energia eólica na região do Ceará, Paraíba, Pernambuco e Rio Grande do Norte, Brasil
} (doi:10.4136/ambi-agua.147)

\author{
Francisco José Lopes de Lima ${ }^{1}$; Jonathan Castro Amanajás ${ }^{1}$; Roni Valter de Souza \\ Guedes $^{1}$; Emerson Mariano da Silva ${ }^{2}$ \\ ${ }^{1}$ Universidade Federal de Campina Grande - UFCG \\ E-mail: thescolopes@yahoo.com.br; jonathan.amanajas@hotmail.com; roniguedes84@yahoo.com.br \\ ${ }^{2}$ Universidade Estadual do Ceará - UECE \\ E-mail: emerson@uece.br
}

\section{RESUMO}

Apresenta-se neste estudo a avaliação da metodologia de Análises Multivariadas: Análises em Componente Principal (ACP) e de Agrupamento (AA), aos dados de velocidade média horária do vento obtida em 28 estações localizadas em quatro Estados do Nordeste brasileiro: Ceará com 10 estações, Paraíba com 5 estações, Pernambuco com 8 estações e Rio Grande do Norte com 5 estações. Todas as estações estão bem distribuídas espacialmente e período de dados entre 1977 e 1981. Os resultados da Análise em Componente Principal (ACP) identificou as regiões litorâneas e serranas como as mais favoráveis para geração de energia eólica, em especial as estações de Acaraú no Ceará e Macau no Rio Grande do Norte, enquanto que Barbalha apresentou-se como a menos favorável, possivelmente devido a sua localização. A Análise de Agrupamento (AA), pelo método Ward, permitiu o agrupamento das estações em seis grupos homogêneos.

Palavras-chave: vento; energia renovável; grupos homogêneos.

\section{Principal Component and Cluster Analysis to study wind to support energy generation in the region of Ceará, Paraíba, Pernambuco and Rio Grande do Norte, Brazil}

\begin{abstract}
This study presents a methodology using multivariate analysis: Principal Component Analysis (PCA) and Cluster Analysis (CA) to analyze data of hourly averaged speed in hours from 28 stations distributed in four states of Northeastern Brazil: Ceará with 10 stations, Paraíba with 5 stations, Pernambuco with 8 stations and Rio Grande do Norte with 5 stations. All stations are well distributed spatially and period of data between 1977 to 1981 . The results of the Principal Component Analysis (PCA) showed that the coastal and mountainous regions have the greatest potential for energy generation results, in particularly at the stations of Acaraú-CE and Macaú-RN, while Barbalha-CE had the lowest potential, possibly due to its location. The Cluster Analysis (CA), using the Ward method, allowed the distribution of the stations into six homogeneous groups.
\end{abstract}

Keywords: wind; renewable energy; homogeneous groups. 


\section{INTRODUÇÃO}

A energia eólica é uma energia limpa e tem origem na dinâmica da atmosfera, gerada a partir do aproveitamento da velocidade dos ventos observados em uma determinada região. No Brasil a exploração dos recursos eólicos, como em muitos países de clima tropical, é relativamente recente, data do início da década passada.

Nesse contexto, cita-se que, com o apoio da ANEEL e do Ministério de Ciência e Tecnologia (MCT), o Centro Brasileiro de Energia Eólica (CBEE), da Universidade Federal de Pernambuco (UEPE), publicou, em 1998, a primeira versão do Atlas Eólico da Região Nordeste, no qual a continuidade desse trabalho resultou no Panorama do Potencial Eólico no Brasil (Silva, 2003; Campos, 2004).

Dessa forma, os diversos levantamentos e estudos observacionais realizados e em andamento (locais, regionais e nacionais), particularmente na região Nordeste do País, vêm fornecendo suporte e motivando a exploração comercial da energia eólica, pela implantação de parques de geração, chamados de parques eólicos, em diversas regiões, que são denominadas de sítios eólicos (Sauer et al., 2006).

Embora o conhecimento gerado por esses levantamentos sejam relevantes do ponto de vista observacional, ainda existem grandes divergências entre especialistas e instituições quanto ao emprego de metodologias para identificação dos potenciais sítios de geração de energia eólica. Isso se deve principalmente à falta de informações, ou seja, a séries temporais longas, sem falhas nos conjuntos de dados de velocidade do vento observados em superfície e à falta de dados de velocidade do vento em altitude, particularmente, na altura em que são instalados os aerogeradores (entre 80 e $120 \mathrm{~m}$ ).

Em relação aos estudos observacionais, que visam caracterizar os regimes predominantes de vento, bem como quantificar os recursos eólicos e identificar possíveis áreas de geração de energia na região Nordeste do Brasil, pode-se destacar o estudo de Barreto et al. (2002) que usaram dados de direção e velocidade do vento à superfície, a 10 metros de altura, proveniente de 77 estações meteorológicas do Instituto Nacional de Meteorologia (INMET), para estudar seu ciclo diário em todo o Nordeste brasileiro. Mostraram que, nas áreas litorâneas, o vento intensifica-se no período diurno atingindo intensidade máxima no iníciomeio da tarde em resposta ao escoamento médio de grande escala e à brisa marítima. Desintensifíca-se no período noturno com a atuação da brisa terrestre, no sentido contrário ao escoamento médio de grande escala, o que ocasiona um mínimo de intensidade no final da noite e início da manhã. Há fortes indícios da penetração da brisa marítima continente adentro em estados do norte do Nordeste, que interage com o escoamento médio e outras circulações locais em áreas de orografias complexas, com máximo secundário em algumas áreas.

O estudo observacional de Silva (2003), para caracterizar os regimes de ventos na região Nordeste do Brasil para aplicação em projetos de centrais eólicas em regiões litorâneas, mostrou que a climatologia observada dos ventos na região Litoral Norte do Nordeste, onde se encontra o litoral do Estado do Ceará, é condicionada principalmente por dois mecanismos eólicos: o comportamento dos ventos alísios, em grande escala, e as brisas marítimas, em escala regional. O primeiro, com periodicidade anual, é regulado pela movimentação da Zona de Convergência Intertropical (ZCIT), e o segundo pela periodicidade diária, regulado apenas pelo gradiente térmico terra-mar.

Assim, concordando com o exposto acima, tem-se como objetivo deste trabalho, investigar a aplicação de metodologias de Análises Multivariadas, por meio da Análises de Componente Principal (ACP) e de Agrupamento (AA), para identificar futuros sítios de geração de energia eólica, em regiões inseridas em quatro Estados do Nordeste brasileiro: Ceará, Paraíba, Pernambuco e Rio Grande do Norte. 
LIMA, F. J. L.; AMANAJÁS, J. C.; GUEDES, R. V. S.; SILVA, E. M. Análises de Componente Principal e de Agrupamento para estudo de ventos para a geração de energia eólica na região do Ceará, Paraíba, Pernambuco e Rio Grande do Norte, Brasil. Ambi-Agua, Taubaté, v. 5, n. 2, p. 188-201, 2010. (doi:10.4136/ambi-agua.147)

\section{MATERIAL E MÉTODOS}

Os dados utilizados neste estudo são séries temporais de velocidades horária média do vento observadas em estações meteorológicas localizadas em regiões de quatro Estados do Nordeste brasileiro: Ceará com 10 estações, Pernambuco com 8, Paraíba e Rio Grande do Norte com 5 cada um, totalizando 28 estações obtidas junto ao banco de dados meteorológicos do Instituto Nacional de Meteorologia (INMET). Informações referentes ao processamento e análise desses dados visando determinar o potencial para aproveitamento de energia eólica são encontradas em Bastos et al. (1987). A distribuição das estações é indicada por números na Figura 1, cujos números sinóticos, siglas, latitudes, longitudes e altitudes constam na Tabela 1.

As medições da velocidade do vento observado, em cada uma dessas estações, são realizadas a 10 metros acima do nível do solo, como recomenda a Organização Meteorológica Mundial (OMM), sendo que os registros são do período de janeiro de 1977 a dezembro de 1981.

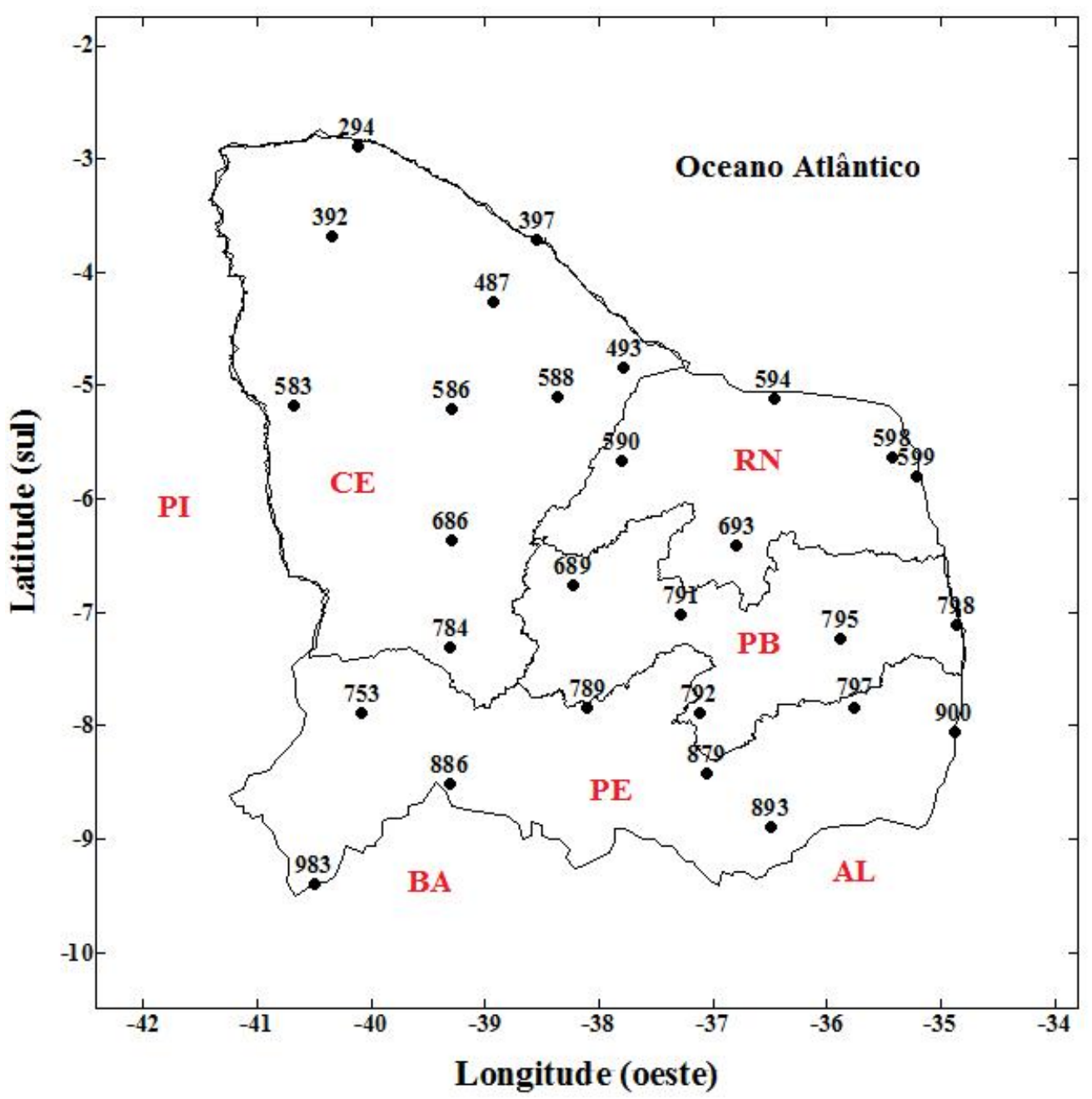

Figura 1. Distribuição espacial de 28 estações localizadas em quatro estados do NEB. O número sinótico das estações inicia-se com 82 , conforme a Tabela 1. 
LIMA, F. J. L.; AMANAJÁS, J. C.; GUEDES, R. V. S.; SILVA, E. M. Análises de Componente Principal e de Agrupamento para estudo de ventos para a geração de energia eólica na região do Ceará, Paraíba, Pernambuco e Rio Grande do Norte, Brasil. Ambi-Agua, Taubaté, v. 5, n. 2, p. 188-201, 2010. (doi:10.4136/ambi-agua.147)

Tabela 1. Relação das estações meteorológicas de superfície do INMET utilizadas no estudo.

\begin{tabular}{|c|c|c|c|c|c|}
\hline Estação & $\mathrm{N}^{\circ}$ Sinótico & Sigla & Lat. (Sul) & Long. (Oeste) & Altitude (m) \\
\hline Acaraú & 82294 & Aca & $2^{\circ} 53^{\prime}$ & $40^{\circ} 07^{\prime}$ & 7 \\
\hline Sobral & 82392 & Sob & $3^{\circ} 42^{\prime}$ & $40^{\circ} 21^{\prime}$ & 75 \\
\hline Fortaleza & 82397 & For & $3^{\circ} 42^{\prime}$ & $38^{\circ} 31^{\prime}$ & 26 \\
\hline Guaramiranga & 82487 & Gua & $4^{\circ} 17^{\prime}$ & $39^{\circ} 09^{\prime}$ & 977 \\
\hline Jaguaruana & 82493 & Jag & $4^{\circ} 50^{\prime}$ & $37^{\circ} 48^{\prime}$ & 15 \\
\hline Crateús & 82583 & Cra & $5^{\circ} 11^{\prime}$ & $40^{\circ} 40^{\prime}$ & 275 \\
\hline Quixeramobim & 82586 & Qui & $5^{\circ} 12^{\prime}$ & $39^{\circ} 18^{\prime}$ & 187 \\
\hline Morada Nova & 82588 & Mor & $05^{\circ} 6^{\prime}$ & $38^{\circ} 23^{\prime}$ & 50 \\
\hline Iguatu & 82686 & Igu & $6^{\circ} 22^{\prime}$ & $39^{\circ} 18^{\prime}$ & 213 \\
\hline Barbalha & 82784 & Bar & $7^{\circ} 19^{\prime}$ & $39^{\circ} 18^{\prime}$ & 405 \\
\hline Apodi & 82590 & Apo & $5^{\circ} 40^{\prime}$ & $37^{\circ} 48^{\prime}$ & 305 \\
\hline Macau & 82594 & Mac & $05^{\circ} 7^{\prime}$ & $36^{\circ} 38^{\prime}$ & 2 \\
\hline Ceará Mirim & 82598 & Cea & $5^{\circ} 38^{\prime}$ & $35^{\circ} 26^{\prime}$ & 40 \\
\hline Natal & 82599 & Nat & $5^{\circ} 48^{\prime}$ & $35^{\circ} 13^{\prime}$ & 8 \\
\hline Cruzeta & 82693 & $\mathrm{Cru}$ & $6^{\circ} 25^{\prime}$ & $36^{\circ} 47^{\prime}$ & 140 \\
\hline São Gonçalo & 82698 & São & $6^{\circ} 50^{\prime}$ & $38^{\circ} 19^{\prime}$ & 235 \\
\hline Patos & 82791 & Pat & $07^{\circ} 1^{\prime}$ & $37^{\circ} 17^{\prime}$ & 250 \\
\hline Monteiro & 82792 & Mon & $7^{\circ} 52^{\prime}$ & $37^{\circ} 07^{\prime}$ & 596 \\
\hline Campina Grande & 82795 & Cam & $7^{\circ} 12^{\prime}$ & $35^{\circ} 51^{\prime}$ & 508 \\
\hline João Pessoa & 82798 & Joã & $07^{\circ} 7^{\prime}$ & $34^{\circ} 53^{\prime}$ & 5 \\
\hline Ouricuri & 82753 & Our & $7^{\circ} 53^{\prime}$ & $40^{\circ} 04^{\prime}$ & 432 \\
\hline Triunfo & 82789 & Tri & $7^{\circ} 50^{\prime}$ & $38^{\circ} 07^{\prime}$ & 1010 \\
\hline Surubim & 82797 & Sur & $7^{\circ} 49^{\prime}$ & $35^{\circ} 45^{\prime}$ & 380 \\
\hline Arcoverde & 82879 & Arc & $8^{\circ} 26^{\prime}$ & $37^{\circ} 04^{\prime}$ & 663 \\
\hline Cabrobó & 82886 & $\mathrm{Cab}$ & $8^{\circ} 30^{\prime}$ & $39^{\circ} 19^{\prime}$ & 350 \\
\hline Garanhuns & 82893 & Gar & $8^{\circ} 51^{\prime}$ & $36^{\circ} 28^{\prime}$ & 866 \\
\hline Recife & 82900 & Ref & $08^{\circ} 3^{\prime}$ & $34^{\circ} 55^{\prime}$ & 5 \\
\hline Petrolina & 82983 & Pet & $9^{\circ} 23^{\prime}$ & $40^{\circ} 30^{\prime}$ & 376 \\
\hline
\end{tabular}

$\mathrm{Na}$ análise dos dados, utilizaram-se as técnicas de Análise Componentes Principais (ACP) e Análise de Agrupamento (AA) nos modos espacial e temporal para definir os principais sistemas contribuintes de variabilidade da velocidade média diária do vento à superfície e suas regiões homogêneas nos quatro estados em estudo, respectivamente.

\subsection{Análise em Componentes Principais (ACP)}

A técnica estatística da Análise em Componentes Principais (ACP) tornou-se popular nas análises de dados atmosféricos após Lorenz (1956). A partir daí, inúmeros pesquisadores fizeram uso de tais técnicas como Ceballos e Braga, (1995), Nery et al. (1999), Esteban et al. (2006), Fragoso e Gomes (2008) e outros que empregaram em uma variedade de aplicações meteorológicas. Outra técnica de análise multivariada muito utilizada em ciências atmosféricas, seja isoladamente ou em conjunto com a ACP, é a Análise de Agrupamento.

As técnicas de análises multivariadas, a exemplo da ACP, são ferramentas poderosas na análise de um número grande de variáveis. Elas permitem reduzir a dimensão da matriz de observações sem perder as informações importantes dos dados originais, investiga o comportamento espaço-temporal das variáveis envolvidas no problema, assim como detecta grupos de variáveis que apresentem comportamento homogêneo. Esse método tem por objetivo a descrição dos dados contidos numa matriz indivíduos-caracteres numéricos: $p$ caracteres são medidos em $n$ indivíduos (Bouroche e Saporta, 1982).

A coleta básica de informações na Análise de Componentes Principais é a matriz de dados (Pandizic, 1988). Em $n$ observações existem $m$ variáveis, então a matriz de dados 
LiMA, F. J. L.; AMANAJÁS, J. C.; GUEDES, R. V. S.; SILVA, E. M. Análises de Componente Principal e de Agrupamento para estudo de ventos para a geração de energia eólica na região do Ceará, Paraíba, Pernambuco e Rio Grande do Norte, Brasil. Ambi-Agua, Taubaté, v. 5, n. 2, p. 188-201, 2010. (doi:10.4136/ambi-agua.147)

normalizada (com média zero e variância um) de velocidade do vento pode ser apresentada como $m \times n$, e designada por $Z$, a partir da qual se obtém a matriz de correlação $R$ dada pela Equação 1.

$$
R=\frac{1}{n-1}(Z)(Z)^{t}
$$

em que $(Z)^{\mathrm{t}}$ é a matriz transposta de $Z$. $R$ é uma matriz simétrica positiva de dimensão (k x k), ela é diagonalizável por uma matriz $A$, de mudança de base, denominada de autovetores. A matriz diagonal $D$ cujos elementos diagonais são os autovalores $(\lambda)$ de $R$, é expressa pela Equação 2.

$D=A^{-1} R A$

Pela ortogonalidade dos autovetores, a inversa de $A\left(A^{-1}\right)$ é igual a sua transposta $\left(A^{t}\right)$. Logo, as Componentes Principais (CPs) $Z_{1}, Z_{2}, \ldots, Z_{n}$ são obtidas por combinações lineares entre a transposta dos autovetores $\left(A^{t}\right)$ e a matriz de observações $(Y)$, ou seja:

$Z=A^{t} Y$

$Y=A Z$

Cada linha de $Z$ corresponde a uma $\mathrm{CP}$ que forma as séries temporais associadas aos autovalores. Os valores de Y do $n$-ésimo local podem ser calculados pela Equação 5.

$Y_{i}=a_{j 1} Z_{1}+a_{j 2} Z_{2}+\ldots+a_{j k} Z_{k}+a_{n p} Z_{p}$

A solução dessa equação é única. Essa solução considera a variação total presente no conjunto das variáveis iniciais, em que a CP1 explica o máximo possível da variância dos dados iniciais, enquanto a CP2 explica o máximo possível da variância ainda não explicada e assim por diante, até a última CPm que contribui com a menor parcela de explicação da variância total dos dados iniciais.

No caso deste estudo, cada CP tem uma porção da variância total dos dados mensais da velocidade do vento, e são ordenadas por ordem decrescente dos autovalores mais significativos de $a_{1}$ em $A$, dada pela Equação 6 .

$$
Z_{i}=\sum_{j=1}^{n} a_{j, i} Y_{i}
$$

A variância total do sistema $(V)$ é definida como a soma das variâncias das variáveis observadas, assim $V$ é dada pela Equação 7.

$$
V=\operatorname{traço~} S=\sum_{i=1}^{p} S_{i i}=\sum_{i=1}^{p} \lambda_{i}
$$

em que $\mathrm{S}$ é a variância das variáveis observadas e $\lambda_{i}$ são os autovalores. $\mathrm{O}$ traço da matriz pode ser entendido também como o somatório da diagonal principal da matriz de correlação.

A variância explicada por cada componente é: 


$$
\alpha_{i}=\frac{\lambda_{i}}{\sum_{i=1}^{p} \lambda_{i}} \cdot 100(\%)
$$

O número escolhido de CPs foi baseado no critério de truncamento de Kaiser, que considera como mais significativos os autovalores cujos valores sejam superiores a unidade (Garayalde et al., 1986).

Neste trabalho, utilizou-se uma rotação ortogonal mantendo a correlação entre as componentes igual a zero, portanto independentes, sendo que tal critério que usa a maximização em cada componente dá origem à técnica chamada de VARIMAX.

\subsection{Análise de Agrupamento (Cluster Analysis)}

Análise de agrupamento foi aplicada a pesquisa geofísica desde 1960. Foi durante essa década que essa técnica se proliferou. Uma pesquisa detalhada da literatura de análise de agrupamento usada nos campos da geofísica foi realizada dando conta que vários métodos de análise de agrupamento foram extensamente usados em tipos diferentes de problemas em pesquisa atmosféricas (Gong e Richman, 1995).

Essa técnica estatística de análise multivariada tem como objetivo principal classificar os indivíduos de uma população que são conhecidos por suas características, em grupos que sejam homogêneos intragrupos e heterogêneos intergrupos. As técnicas objetivas de agrupamentos diminuem a subjetividade, pois quantificam a similaridade ou dissimilaridade entre indivíduos. Dentre os vários métodos ou algoritmos de classificação de grupos estão aqueles que utilizam as técnicas hierárquicas. Neste a partição se dá a partir de um número de grupo não definido inicialmente, em que os grupos majoritários são divididos em subgrupos minoritários agrupando aqueles indivíduos que apresentam características semelhantes.

A classificação dos indivíduos em grupos distintos é feita a partir de uma função de agrupamento denominada distância ou similaridade e de um critério matemático de agrupamento (Bouroche e Saporta, 1982).

A distância Euclidiana é a medida de dissimilaridade mais comumente usada em agrupamentos, embora muitas outras medidas de distância existam. Uma discussão detalhada de várias dissimilaridades é apresentada em Duran e Odell (1974).

Considere $p \times n$ dados uma matriz $X$ em espaço dimensional $p$ as distâncias euclidianas entre as entidades $X_{i}$, e $X_{j}$ é dada pela Equação 9.

$$
d_{i j}=\left[X_{i}-X_{j}\right]=\left[\sum_{k=1}^{P}\left(X_{i, k}-X_{j, k}\right)^{2}\right]^{1 / 2}
$$

Tanto a distância euclidiana, medida de dissimilaridade, quanto o coeficiente de correlação, medida de similaridade, podem ser usados na determinação dos grupos. Para esse fim existem dois métodos de agrupamento, os hierárquicos e os não hierárquicos. Nos métodos hierárquicos vários critérios de agrupamentos são possíveis, dentre eles optou-se pelo método de Ward (1963).

Esse método procura por partições que minimizem a perda associada a cada agrupamento (Everitt, 1974; Bussab et al., 1990; Mingoti, 2005). Essa perda é quantificada pela diferença entre a soma dos erros quadráticos de cada padrão e a média da partição em que está contido. A soma dos erros quadrados é definida como:

$$
S Q D=\sum_{i=1}^{n} x_{i}^{2}-\frac{1}{n}\left(\sum_{i=1}^{n} x_{i}\right)^{2}
$$

em que $n$ é o número total de elementos do agrupamento e $x_{i}$ é o i-ésimo elemento do agrupamento. 
LIMA, F. J. L.; AMANAJÁS, J. C.; GUEDES, R. V. S.; SILVA, E. M. Análises de Componente Principal e de Agrupamento para estudo de ventos para a geração de energia eólica na região do Ceará, Paraíba, Pernambuco e Rio Grande do Norte, Brasil. Ambi-Agua, Taubaté, v. 5, n. 2, p. 188-201, 2010. (doi:10.4136/ambi-agua.147)

Algumas características desse método são: apresenta bons resultados tanto para distâncias euclidianas quanto para outras distâncias; pode apresentar resultados insatisfatórios quando o número de elementos em cada grupo é praticamente igual; tem tendência a combinar grupos com poucos elementos.

As etapas descritas anteriormente, embora instrutivas acerca do processo de agrupar indivíduos, não facilitam a interpretação dos resultados a respeito de como serão obtidos os grupos e o número deles num processo de agrupamento. Necessita-se de instrumentos mais apropriados, um deles é o dendrograma que é uma representação gráfica muito usada na análise de agrupamento para apresentar o resultado de um agrupamento.

\section{RESULTADOS}

As Figuras 2 e 3 mostram a variabilidade espacial e temporal da velocidade média horária do vento observado nas 28 estações em estudo.

Observa-se na Figura 2 que as estações localizadas na cidade de Macau no Rio Grande do Norte, Campina Grande na Paraíba, Guaramiranga e Acaraú no Ceará obtiveram médias de velocidade horária do vento igual ou acima de $4,0 \mathrm{~m} / \mathrm{s}$ em superfície. Enquanto que a cidade de Barbalha no Ceará obteve valores médios de velocidade média horária do vento abaixo de $2,0 \mathrm{~m} / \mathrm{s}$ em superfície, as demais localidades apresentam valores que variam entre, aproximadamente $2,5 \mathrm{~m} / \mathrm{s}$ e $4,0 \mathrm{~m} / \mathrm{s}$.

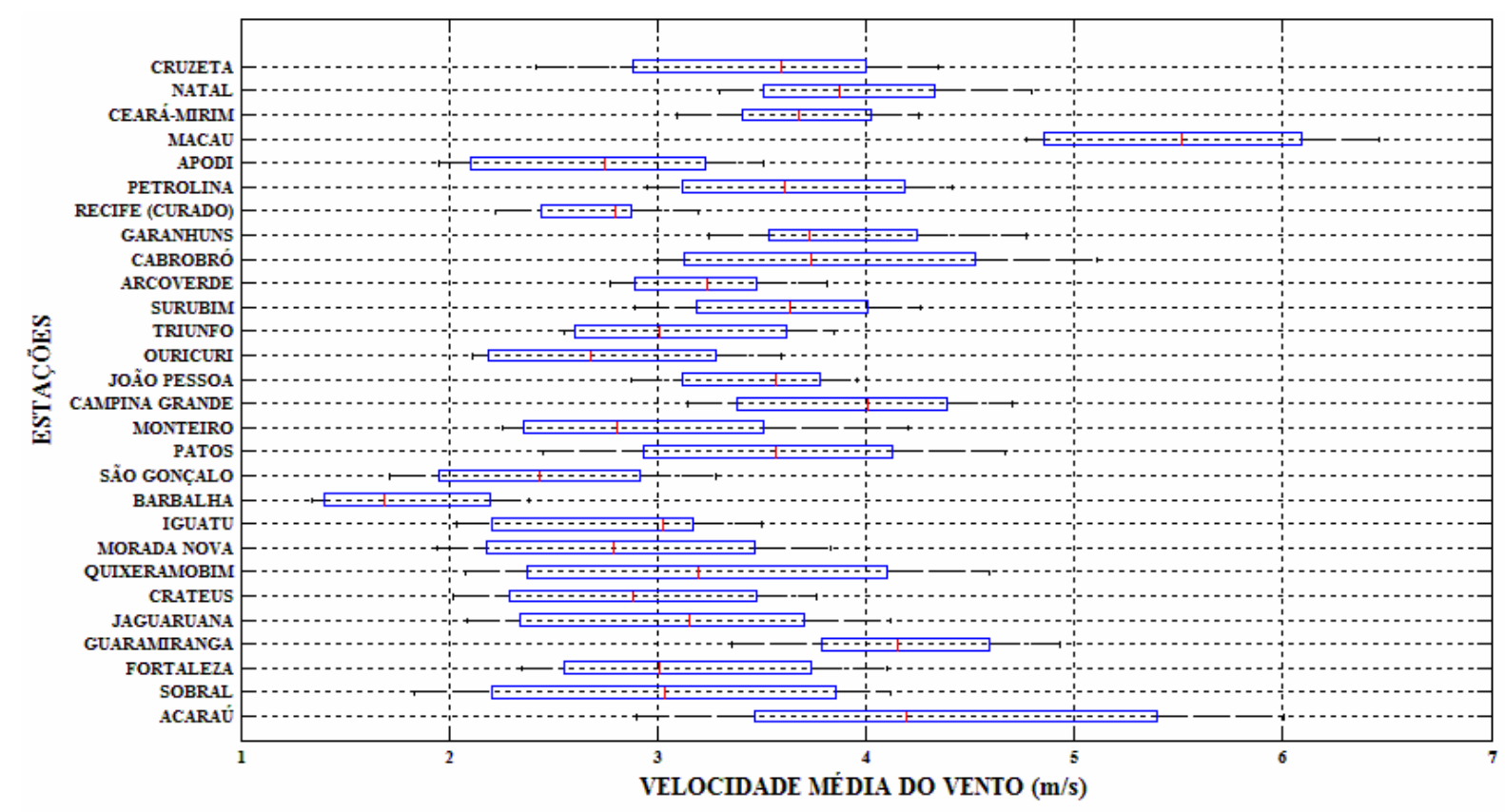

Figura 2. Gráfico de caixa que mostra a variabilidade espacial dos dados de velocidade média horária do vento observado nas 28 estações em estudo.

A Figura 3 mostra a variação temporal dos dados em estudos e verifica-se que os menores valores de velocidade média do vento, observados na região, ocorrem nos meses de fevereiro a junho. Meses que correspondem, em média, ao período chuvoso nessas regiões (Alves et al., 2005; Silva et al., 2007). Assim, tem-se um período em que os ventos em superfície são menos intensos, isto ocorre, de certa forma, pelo posicionamento da Zona de Convergência Intertropical (ZCIT). Enquanto que nos meses de julho a janeiro, período seco, nessas regiões, tem-se os maiores valores de velocidade média do vento observado, e assim, tem-se um período em que os ventos em superfície são mais intensos. 
LIMA, F. J. L.; AMANAJÁS, J. C.; GUEDES, R. V. S.; SILVA, E. M. Análises de Componente Principal e de Agrupamento para estudo de ventos para a geração de energia eólica na região do Ceará, Paraíba, Pernambuco e Rio Grande do Norte, Brasil. Ambi-Agua, Taubaté, v. 5, n. 2, p. 188-201, 2010. (doi:10.4136/ambi-agua.147)

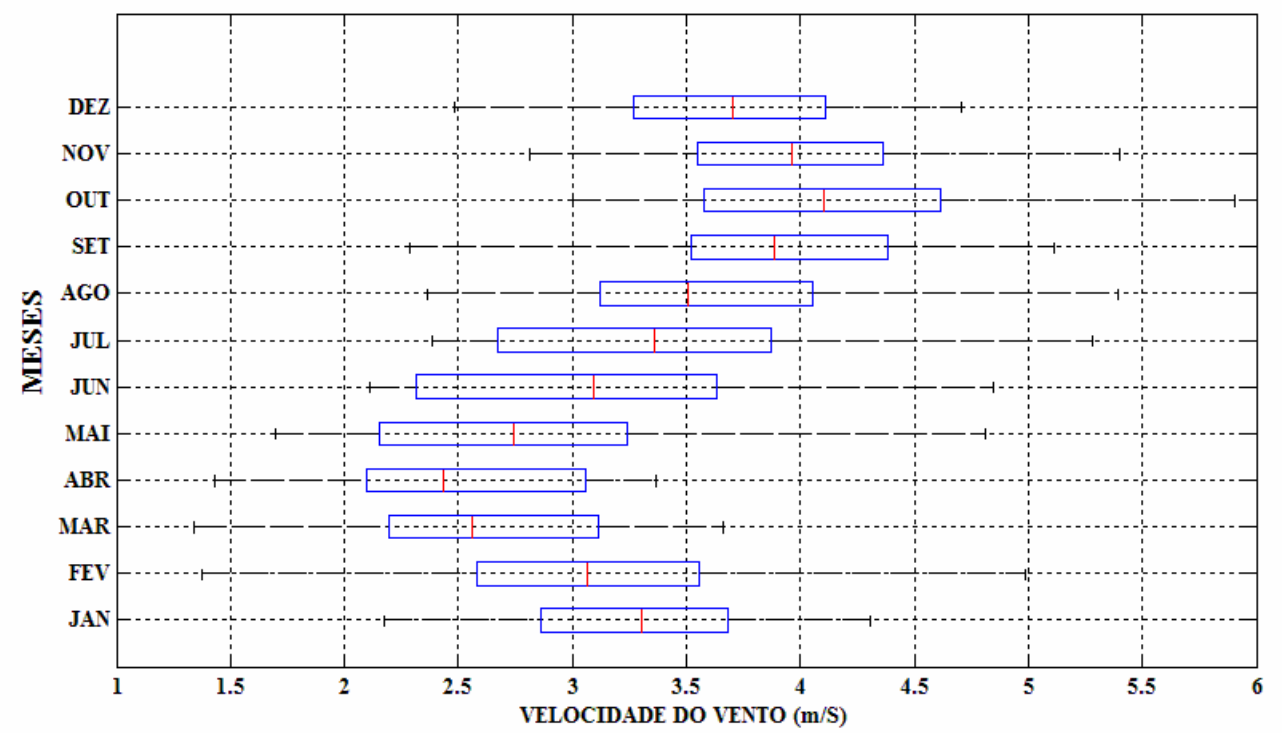

Figura 3. Gráfico de caixa que mostra a variabilidade temporal dos dados de velocidade média horária do vento observados para as 28 estações em estudo.

Para investigar o comportamento espacial da velocidade média horária do vento no período compreendido entre os anos de 1977 e 1981 foi gerado um mapa com a média anual da velocidade, mostrado na Figura 4.

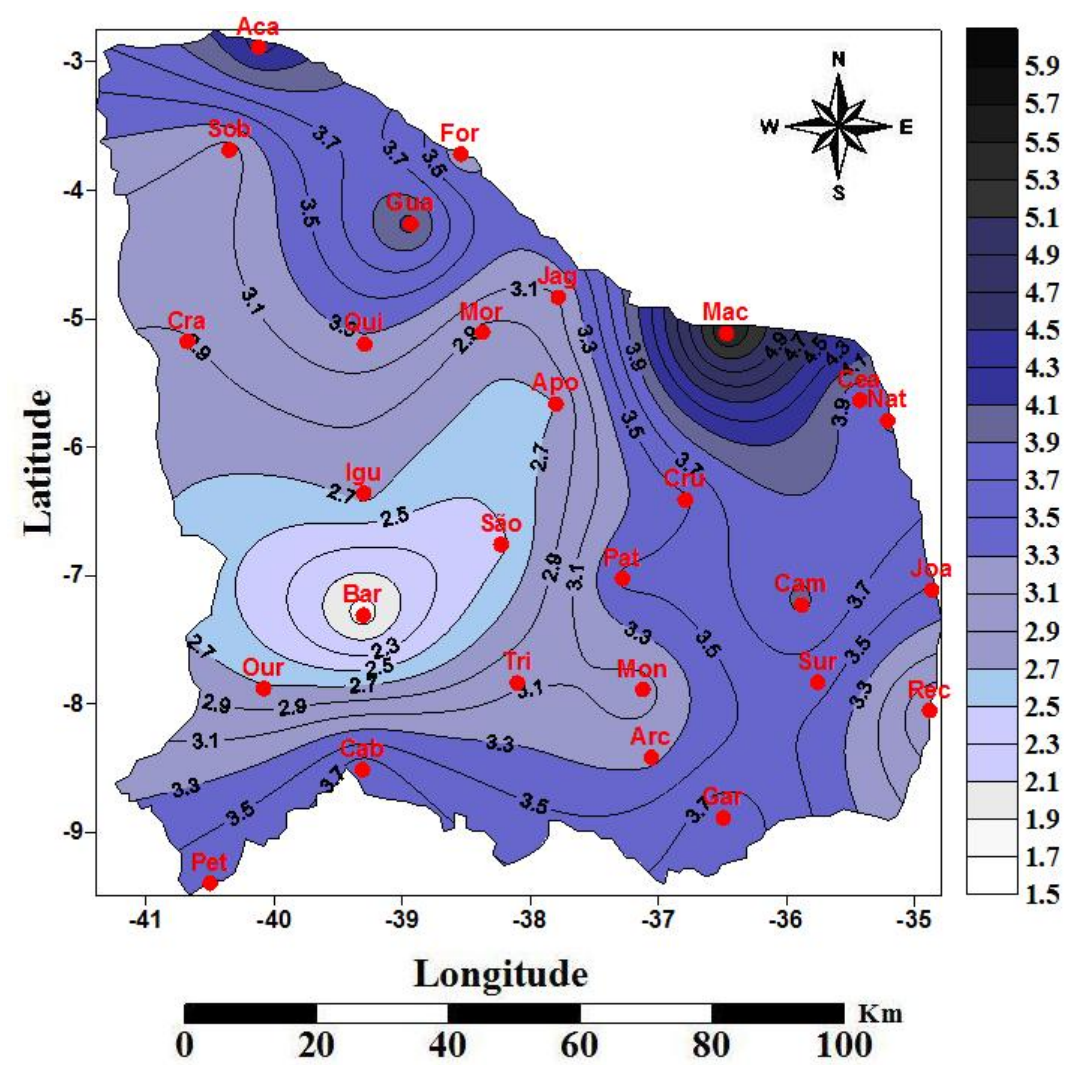

Figura 4. Distribuição espacial da velocidade média anual do vento nos cincos estados em estudo.

Observa-se na Figura 4, que os maiores valores de velocidade média horária do vento, em geral, ocorrem na faixa litorânea, com destaque para a cidade de Macau no litoral do Rio Grande do Norte e Acaraú no litoral do Estado do Ceará. No entanto, algumas regiões no interior da região em estudo merecem destaque, como é o caso das cidades de Petrolina, 
LIMA, F. J. L.; AMANAJÁS, J. C.; GUEDES, R. V. S.; SILVA, E. M. Análises de Componente Principal e de Agrupamento para estudo de ventos para a geração de energia eólica na região do Ceará, Paraíba, Pernambuco e Rio Grande do Norte, Brasil. Ambi-Agua, Taubaté, v. 5, n. 2, p. 188-201, 2010. (doi:10.4136/ambi-agua.147)

Cabrobó e Garanhuns no Estado de Pernambuco, Campina Grande na Paraíba e Guaramiranga no Ceará.

Os menores valores de velocidade média anual do vento foram encontrados nas estações meteorológicas de Barbalha, Iguatu e Crateús no Ceará e São Gonçalo na Paraíba. Essa distribuição caracteriza-se pela atuação de fenômenos meteorológicos que atuam na região nordeste ao longo do ano, os quais se destacam: a Zona de Convergência Intertropical (ZCIT), Sistemas Frontais, Vórtices Ciclônicos de Ar Superior (VCAS) e Distúrbios de Leste (Sistemas de Brisas e ventos alísios de Sudeste), como citado em Souza e Silva (2003).

Segundo a sequência dos autovalores, mostrados na Tabela 2, obtidos a partir do critério de Kaiser, as duas primeiras componentes explicam $93,77 \%$ da variância do vento observado nas regiões em estudo. Assim, a primeira componente com rotação explica 48,64\% da variância e apresenta maiores valores nos meses de janeiro a março e setembro a dezembro nos anos de 1977 a 1981. A segunda componente explica 45,13\% da variância total dos dados e tem maiores valores nos meses de abril a setembro, como observado na Figura 5.

Tabela 2. Sequência dos autovalores na ordem decrescente e a contribuição da variância total dos dados em estudo rotacionados.

\begin{tabular}{c|c|c|c}
\hline Componentes & Autovalor & Variância Explicada (\%) & Variância Acumulada (\%) \\
\hline 1 & 9,94 & 48,64 & 48,64 \\
2 & 1,32 & 45,13 & 93,77 \\
$\ldots$ & $\ldots$ & $\ldots$ & $\ldots$ \\
12 & 0 & 0 & 100 \\
\hline
\end{tabular}

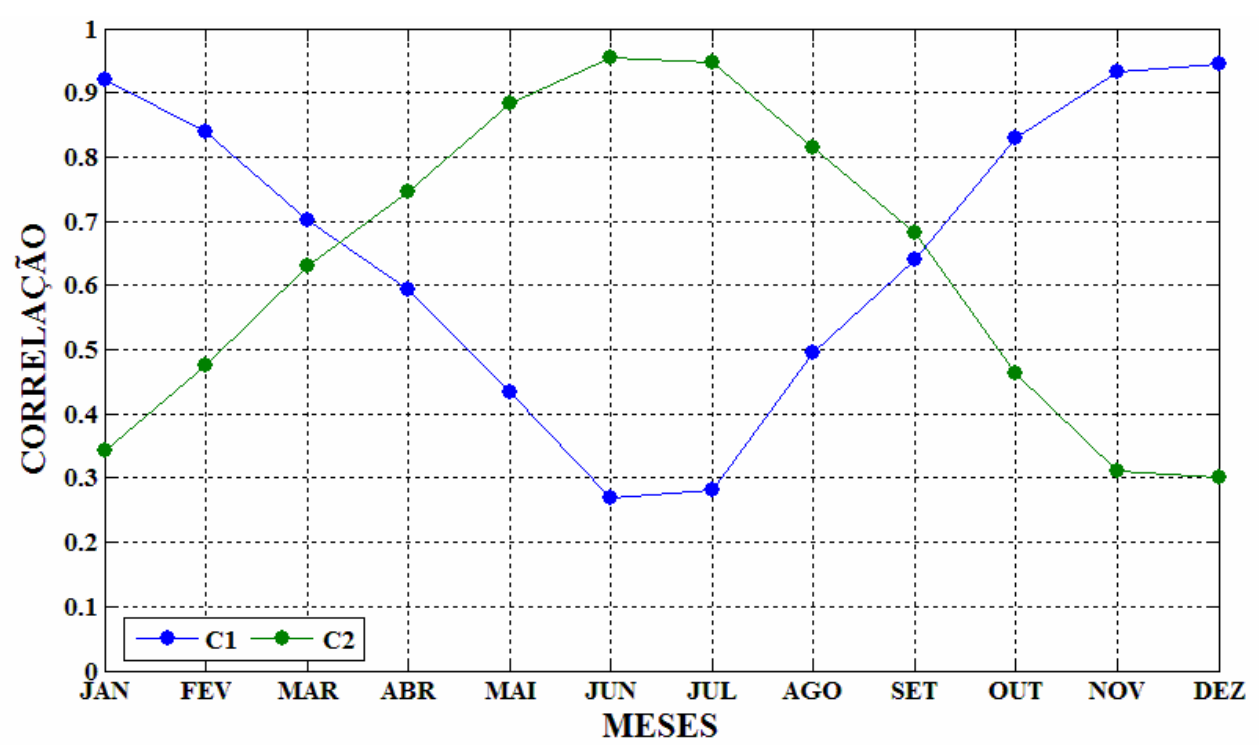

Figura 5. Contribuição das duas componentes, variação temporal. Componente 1 (C1), Componente 2 (C2).

$\mathrm{Na}$ distribuição espacial associada à primeira $\mathrm{CP}$, mostrada na Figura 6, verificam-se altas contribuições na área litorânea e em alguns pontos do interior. Particularmente no Ceará, destacam-se as cidades de Acaraú, Sobral, Quixeramobim e Guaramiranga. Assim, ressalta-se que esse fato se deve às influências da localização da ZCIT, mais ao Norte, no período seco, período em que se registra intensificação das circulações de brisas marítimas e terrestres, bem como das brisas de vale e montanha, observadas na região. No Rio Grande do Norte, Paraíba e Pernambuco, têm destaque as estações de Macau, Campina Grande e Garanhuns, desempenho que se deve às influências dos Distúrbios de Leste, que são sistemas que atuam desde o Norte do Rio Grande do Norte até a Bahia. 


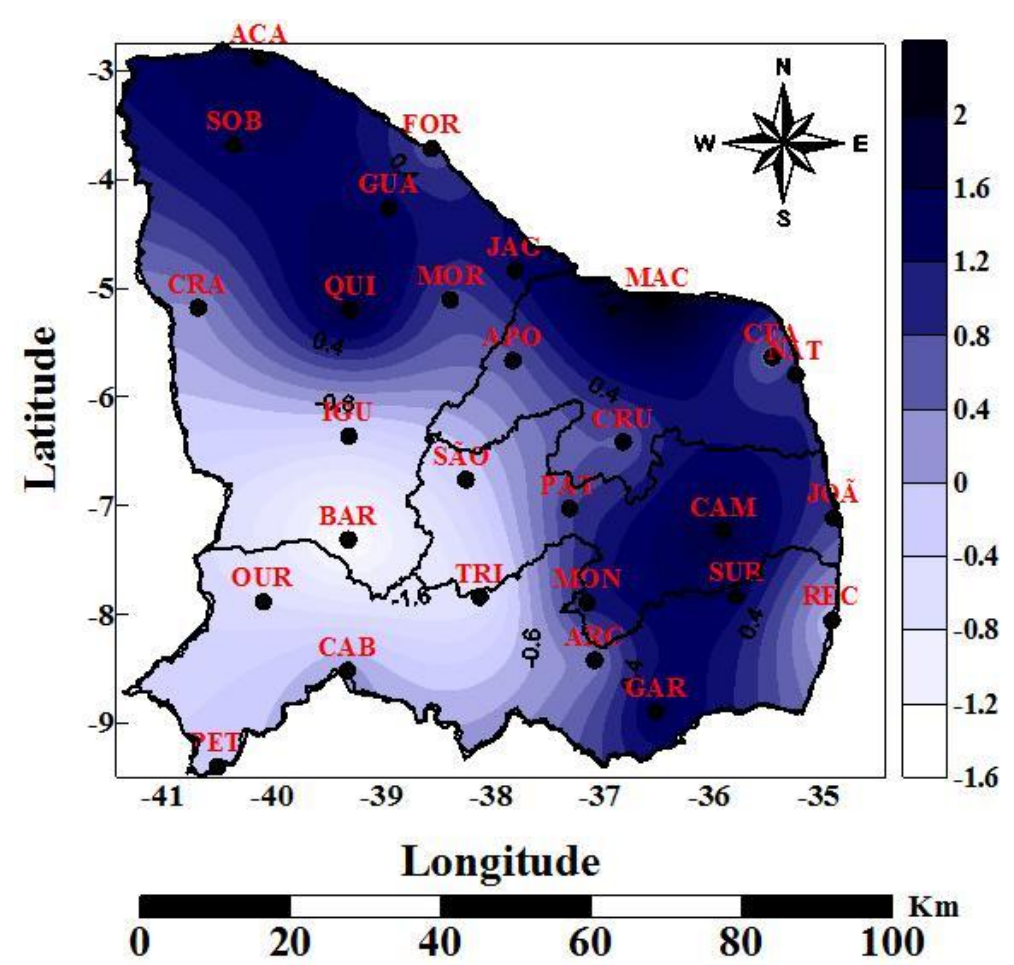

Figura 6. Distribuição espacial da primeira CP.

A distribuição espacial referente à segunda $\mathrm{CP}$, mostrada na Figura 7, continua explicando as estações de Macau, Acaraú, e Guaramiranga que são estações de localização geográfica privilegiada, com a forte presença de fenômenos meteorológicos locais. Nessa segunda CP também se têm explicadas as influências nas estações de Petrolina, Cabrobró, Triunfo e Garanhuns em Pernambuco. No entanto, a segunda CP não explicou a estação de Barbalha, localizada no Estado do Ceará. A Figura 8 mostra a localização geográfica e o relevo das estações de Macau/RN e Barbalha/CE, o que justifica o melhor e o pior resultado encontrado com a aplicação dessa metodologia, uma vez que Macau está localizado no litoral do RN e Barbalha em um vale no Cariri do Ceará.

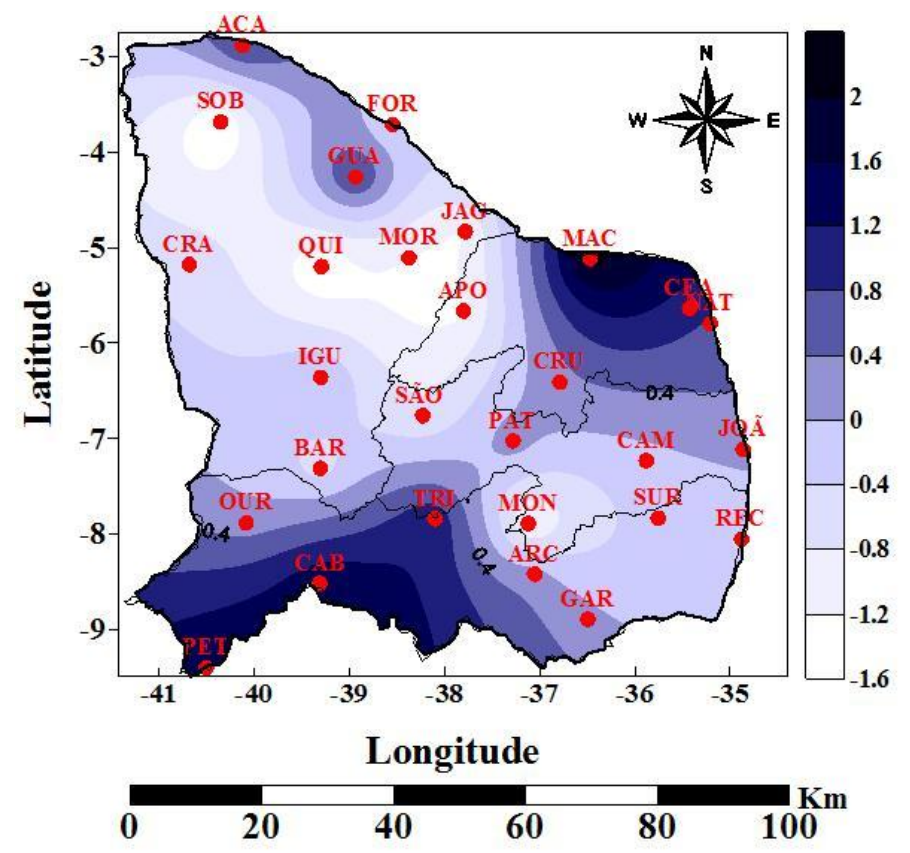

Figura 7. Distribuição espacial da segunda Carga. 


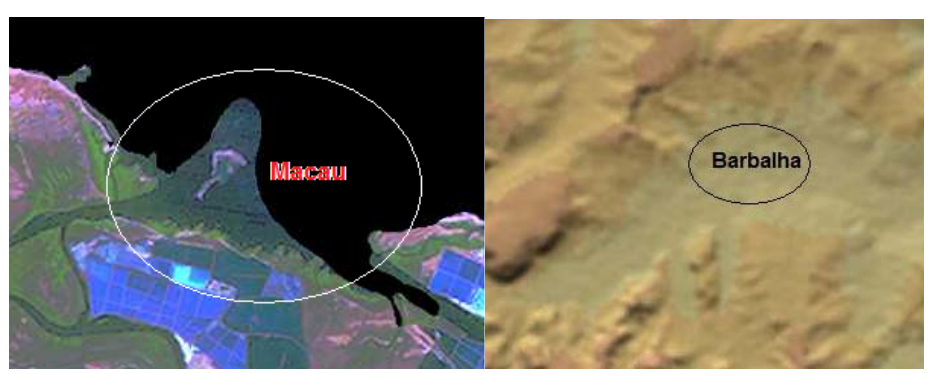

Figura 8. Localização geográfica e relevo de Macau no Rio Grande do Norte e Barbalha no Ceará.

O agrupamento das 28 estações observadas em grupos homogêneos foi realizado pelo método de Ward, a distância Euclidiana simples foi usada como função de agrupamento para medir a similaridade ou dissimilaridade entre as estações.

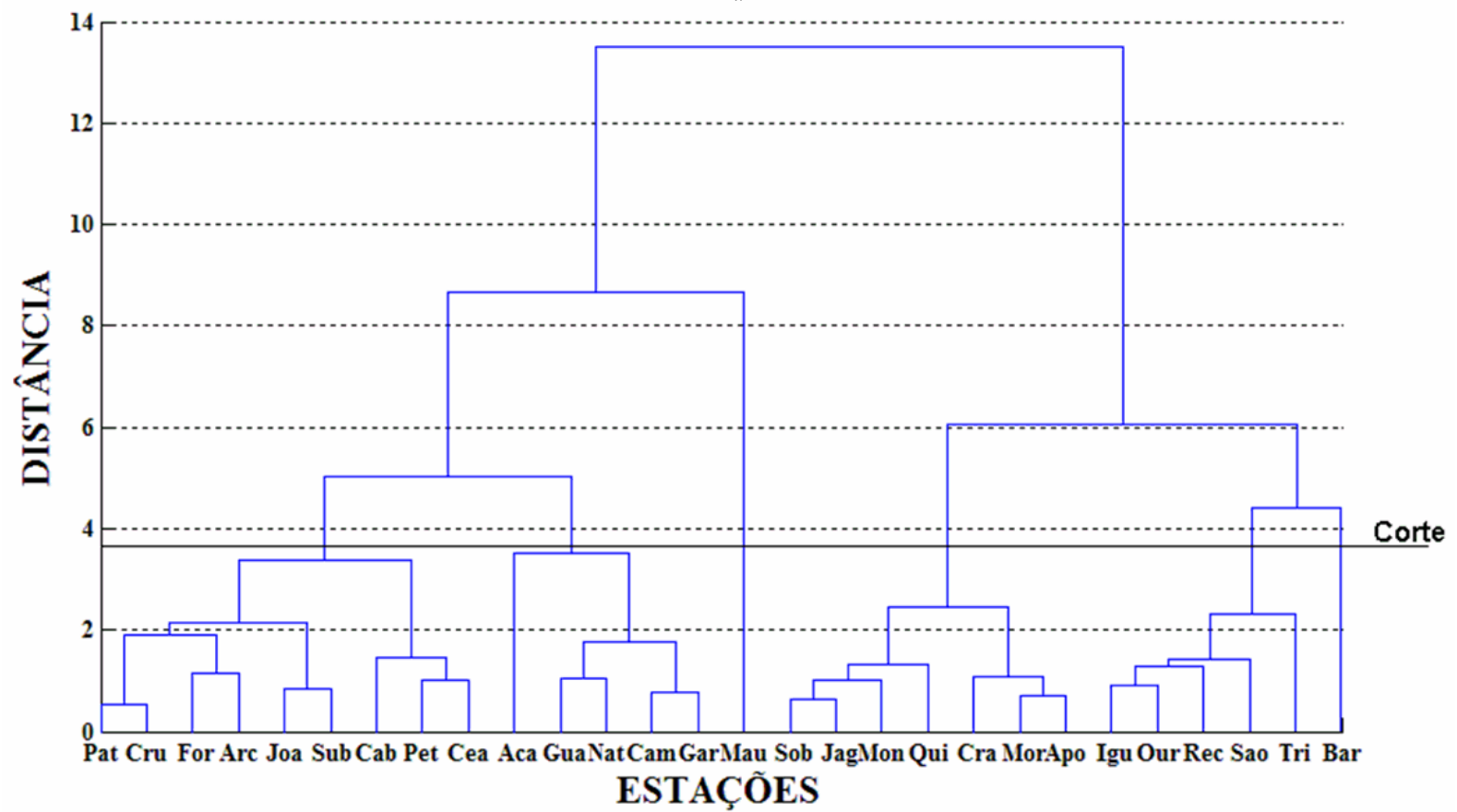

Figura 9. Dendrograma resultante da análise objetiva das 28 estações meteorológicas usando o método aglomerativo hierárquico de Ward.

As 28 estações investigadas, em regiões dos quatro estados nordestinos, foram divididas em seis sub-regiões homogêneas de velocidade média horária do vento, como mostrado na Figura 9. Os grupos foram obtidos pelo Método de Ward, as regiões homogêneas e suas principais características estão descritas na Figura 10.

Podem-se definir seis grupos ou regiões homogêneas em relação ao regime de vento observado. O primeiro grupo, ou região homogênea, é composto apenas pela estação de $\mathrm{Macau} / \mathrm{RN}$, a mais propícia para geração de energia eólica. O segundo grupo (em azul na Figura 10) é formado pelas estações com altos valores de velocidade do vento observado em superfície, que são: Garanhuns/PE, Campina Grande/PB, Natal/RN, Acaraú e Guaramiranga/CE. O terceiro grupo (em vermelho na Figura 10) é formado por cidades localizadas no litoral, Fortaleza/CE, João Pessoa/PB, Ceará Mirim/RN, e no interior, Petrolina, Cabrobó, Arcoverde e Surubim/PE, Patos/PB e Crateús/CE.

No quarto grupo (em verde escuro) se encontra o Alto Apodi/RN, Jaguaruana/CE, Crateú/CE, Morada Nova/CE e Quixeramobim/CE área localizada dentro da faixa litorânea do Ceará. No quinto (em verde claro), têm-se as estações de Iguatu/CE, Ouricuri, Triunfo e Recife/PE e São Gonçalo/PB. 
LIMA, F. J. L.; AMANAJÁS, J. C.; GUEDES, R. V. S.; SILVA, E. M. Análises de Componente Principal e de Agrupamento para estudo de ventos para a geração de energia eólica na região do Ceará, Paraíba, Pernambuco e Rio Grande do Norte, Brasil. Ambi-Agua, Taubaté, v. 5, n. 2, p. 188-201, 2010. (doi:10.4136/ambi-agua.147)

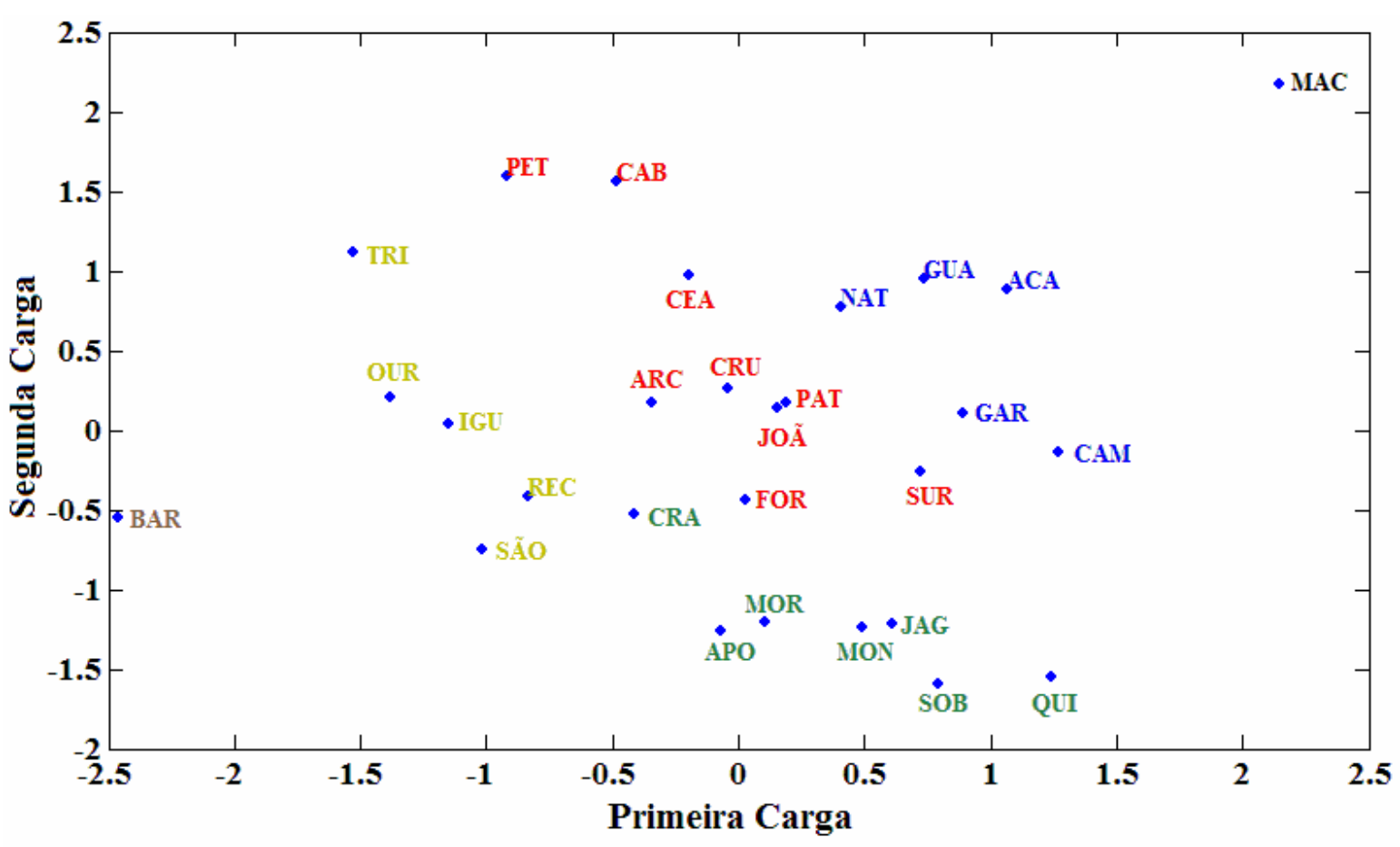

Figura 10. Distribuição das estações em relação às cargas e os seis grupos homogêneos obtidos pelo método de Ward.

Por fim, tem-se o sexto grupo que é representado apenas pela estação de Barbalha/CE, que devido a sua localização geográfica apresenta os menores valores de velocidades média horária do vento dentre as estações investigadas. Na Figura 11, tem-se o mapa da região geográfica com a localização das 28 estações dividida em seis grupos homogêneos.

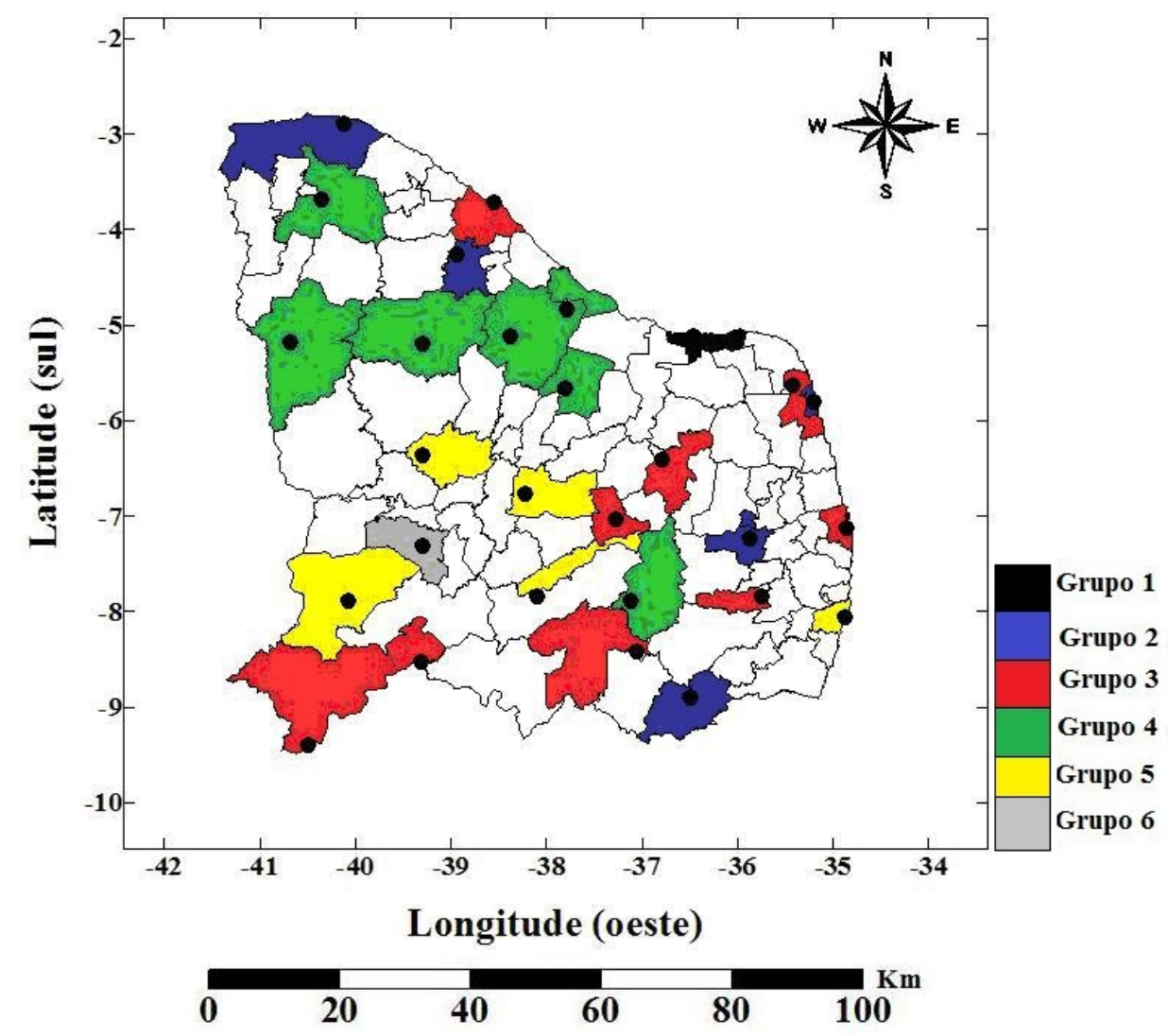

Figura 11. Distribuição das regiões homogêneas em relação às cargas divididas em seis grupos pelo método de Ward. 


\section{CONCLUSÕES}

Os métodos utilizados no processo de caracterização do potencial eólico, segundo a variabilidade espacial da velocidade média horária do vento, mostraram-se capazes de identificar os principais fenômenos atmosféricos atuantes nos estados do Ceará, Paraíba, Pernambuco e Rio Grande do Norte.

Os padrões temporais relacionados à primeira componente comum das velocidades média horária do vento apresentaram bons resultados para os meses de seca, mostrando que o deslocamento meridional da ZCIT mais ao norte de sua climatologia é o principal mecanismo atmosférico que define o comportamento do vento nessa época do ano. A segunda componente apresenta bons resultados nos meses de abril a agosto e são associados a fenômenos meteorológicos locais, tais como brisas marítimas.

A classificação da velocidade média horária do vento usando o método aglomerativo de Ward, segundo o critério da inércia, possibilitou a obtenção de seis grupos homogêneos na região em estudo.

As estações de Macau e Barbalha obtiveram o melhor e o pior resultado desse estudo respectivamente, ficando em grupos isolados das outras estações. Macau ficou no grupo um e Barbalha, no grupo seis.

\section{REFERÊNCIAS}

ALVES, J. M. B.; FERREIRA, F. F.; CAMPOS, J. N. B. Movimento vertical e índices atmosféricos associados às Células de Hadley e Walker em anos de contrastes climáticos: relação com as chuvas do setor norte do nordeste do Brasil - SNNEB. Revista Brasileira de Meteorologia, v. 20, n. 01, p. 113-122, 2005.

BARRETO, A. B.; ARAGÃO, M. R. S. Estudo do ciclo diário do vento à superfície no nordeste do Brasil. In: CONGRESSO BRASILEIRO DE METEOROLOGIA, 12. 2002, Foz do Iguaçu. Anais... Foz do Iguaçu: Sociedade Brasileira de Meteorologia, 2002. 1 CD-ROM.

BASTOS, E. J. B.; CEBALLOS, J. C.; SOBRAL, Z. R.; SIMÕES, F. Distribuição estatística da energia eólica no nordeste. Inventário Energético do Nordeste. Fontes Energéticas Brasileiras, v. 1, p. 29-33, 1987.

BOUROCHE, J- M.; SAPORTA, G. Análise de dados. Rio de Janeiro: Zahar, 1982. 117p.

BUSSAB, W. O.; MIAZAKI, E. S.; ANDRADE, D. Introdução à análise de agrupamentos. São Paulo: Associação Brasileira de Estatística, 1990. 105p.

CAMPOS, F. G. R. Geração de energia a partir de fonte eólica com gerador assíncrono conectado a conversor estático duplo. 2004. 137f. Dissertação (Mestrado em Engenharia) - Escola Politécnica da Universidade de São Paulo, São Paulo, 2004.

CEBALlOS, J. C.; BRAGA, C. C. Missing data assessment in a solarimetric network. Int. J. Climatol., v. 15, p. 325-340, 1995.

DURAN. B. S.; P. L. ODELL. Cluster analysis. Velarg: Asurvey Springer, 1974. 137p.

ESTEBAN, P.; MARTIN-VIDE, J.; MASES, M. Daily atmospheric circulation catalogue for western Europe using multivariate techniques. Int. J. Climatol., v. 26, p. 1501-1515, 2006.

EVERITT, B. S. Cluster analysis. London: Heinemann Educational Books, 1974. 121p. 
FRAGOSO, M.; GOMES, P. T. Classification of daily abundant rainfall patterns and associated large-scale atmospheric circulation types in Southern Portugal. Int. J. Climatol., v. 28, p. 537-544, 2008.

GARAYALDE, E. J. G.; SILVA, M. G. A. DA; TAVARES, A. DE SÁ. Classificação mesoclimática da região sul do Brasil pela análise de componentes principais. In: CONGRESSO INTERAMERICANO DE METEOROLOGIA, 1., CONGRESSO BRASILEIRO DE METEOROLOGIA, Brasília, 1986. Anais... Brasília: Sociedade Brasileira de Meteorologia, 1986. p.119-124.

GONG, X.; RICHMAN, M. B. On the application of analysis to growing seaso precipitation data in North East of the Rockies. J. Climate, v. 8, p. 897-924, 1995.

LORENZ, E. N. Empirical orthogonal functions and statistical weather prediction. Cambridge: $\quad$ MIT, $1956.49 \mathrm{p}$ Disponível em: $<$ http://www.o3d.org/abracco/Atlantic/Lorenz1956.pdf>. Acesso: 20 ago. 2010.

PANDZIC, K. Principal component analysis of precipitation in the Adriatic-Pannonian área of Yugoslavia. J. Climatol., v. 8, p. 357-370, 1988.

MINGOTI, S. A. Análise de dados através de métodos de estatística multivariada: uma abordagem aplicada. Belo Horizonte: Editora da UFMG, 2005.

NERY, J. T.; SANSIGOLO, C. A.; MARTINS, M. L. O. F. Análise de fatores comuns e agrupamentos das temperaturas mínimas de inverno no Estado do Paraná. In: CONGRESSO BRASILEIRO DE AGROMETEOROLOGIA, 11., Florianópolis, 1999. Anais... Florianópolis: Sociedade Brasileira de Agrometeorologia, 1999. p. 1036-1043.

SAUER, I. L.; QUEIROZ, M. S.; MIRAGAYA, J. C. G.; MASCARENHAS, R. C.; QUINTINO JÚNIOR, A. R. Energias renováveis: ações e perspectivas na Petrobras. Bahia Análise \& Dados, v. 16, n. 1, p. 9-22, 2006.

SOUZA, E. P.; SILVA, E. M. Impacto da implementação de uma parametrização de convecção rasa em um modelo de mesoescala: descrição e testes da sensibilidade do esquema. Revista Brasileira de Meteorologia, v. 18, n. 1, p. 33-42, 2003.

SILVA, G. R. Características de vento da região nordeste: análise, modelagem e aplicações para projetos de centrais eólicas. 2003. 131f. Dissertação (Mestrado em Engenharia Mecânica) - Universidade Federal de Pernambuco, Recife, 2003.

SILVA, E. M.; ALVES, J. M. B.; CASTRO, M. A. H. C.; VIERA, V. P. P. B.; CAMPOS, J. N. B. Uma aplicação de conjuntos difusos na otimização do prognóstico de consenso sazonal de chuva no nordeste do Brasil. Revista Brasileira de Meteorologia, v. 20, n. 1, p. 113-122, 2007.

WARD, J. H. Hierarchical grouping of otimize an objetive function. J. American Statistical Association, v. 58, p. 236-244, 1963. 